\title{
The Effect of Management Control System on Performance Measurement System at Small Medium Hotel in Malaysia
}

\author{
Che Zuriana Muhammad Jamil and Rapiah Mohamed
}

\begin{abstract}
Performance measurement system (PMS) is one of the main functions in management roles and reflects the strategic goals of firms. PMS particularly support the management control system (MCS) to manage increasing complexity. Traditionally, PMS models are more horizontal; process oriented and focuses on stakeholder needs. Therefore, it is interesting to consider MCS in designing PMS to overcome the weakness of traditional PMS and to improve overall performance. Specifically, the objective of the study is to investigate the role played by the MCS in the PMS design in the context of the Malaysian SMEs hotels. The study employs contingency theory and using four Simons' levers of control as intervening variables to explain the relationship. Data is collected by survey at small medium hotel sectors in the Northern part of Peninsular Malaysia. The study found that PMS is correlated to an each of the four selected individual management control system (MCS) and also suggest that the development of PMS will influence the overall performance in small medium hotel sector through the acting of MCS.
\end{abstract}

Index Terms-Performance measurement system, management control system, SMEs hotel.

\section{INTRODUCTION}

Performance measurement system (hereafter called PMS) is a topic which has been aggressively discussed by both academics and practitioners since the early 1990s but rarely defined. Good design of PMS should consider multidimensional nature which will affect the performance of the whole organization. Today, in order for firms to compete in globalised and turbulent market and at the same time need to satisfy all their stakeholders, firms should move along all performance dimensions [1], [2]. According to [2], there are three different levels of performance measurement which are the individual measures, the performance measurement system and the relationship between the PMS and the environment within which it operates. The ability of keeping the PMS continuously updated is a challenge for every firm, but particularly for small and medium sized enterprise (hereafter called SME). [3] mentioned that SMEs often do not understand the potential advantages of PMS as these systems are perceived as an obstacle to the flexibility of SMEs. Even though, some SMEs try to implement a system designed for large firms [4]) but, it would be unwise for SMEs to copy the approach of the large firms due to the different environment.

As performance measurement is one of the main

Manuscript received May 5, 2013; revised July 4, 2013.

Che Zuriana Muhammad Jamil is with Universiti Utara Malaysia (email: zuriana@uum.edu.my). functions in management roles to show to what extent the firm has achieved their pre-designed strategies and goals, it is a right time to study on PMS in SME in Malaysia. The issue is focused on the Management Control System (hereafter called MCS) employed in small medium hotel sector with regard to performance measurement. Specifically, the issue is proposed in order to obtain a better understanding of the relationships between good performance measures (both financial and non-financial) and the four lever dimensions of MCS; Interactive control system, Belief control system, Boundary control system and Diagnostic control system. This issue explores whether appropriate PMSs are used to evaluate changes in business results as well as a means of monitoring the management practices to assess their impact on these results. At present, little is known about the self-review activities of small hotel operators and the extent of their focus on operational and financial outcome improvements. Furthermore, there is little evidence of whether they link specific MCS activities to the overall performance of the business.

Therefore, this study tries to develop an appropriate PMS framework that SMEs can use to evaluate their performance and identify the factors and directions for improvement. By negotiating MCS in the framework, it is hoped that a new framework can be used to improve the SMEs performance.

\section{LITERATURE REVIEW}

\section{A. Performance Measurement System (PMS) at SME}

In order to develop a PMS assessment tool for SMEs, it is necessary to identify which are characteristics of a PMS that enable the company to effectively and efficiently measure and manage its performance. SMEs, according to [5] and [6], have a flat structure, which allows clear, uninterrupted streams of communication. In addition, [5] point out that current performance measurement in SMEs is limited by barriers of limited resources and strategy oriented processes.

According to [1], important elements that considered as 'best practices' for PMS are classified into two aspects, characteristics and requirements. All the characteristics have been grouped into two main categories; external environment and internal environment. As [7] mentioned, external environment represents the context in which the organizational operates and the factors essentially outside the control of organizational. While, internal environment includes the factors which are inside the company or under the managers' control, like the resources, both human and financial, and the way they are managed (managerial practice). With regards to requirements, [1] highlighted that 
PMS should divide into three categories; performance requirements, characteristics of the PMS as whole, requirements of the process of performance measurement and PMS use.

There are two models which are developed purposely to performance measurement in SMEs; Organizational Performance measurement [8] and Integrated Performance measurement for small firms [9]. However, literature claims that it is still not clear whether these two models applied to the needs of SMEs. As [10] highlighted the fact that SMEs do not usually implement integrated PMS and that they are not aware of the existence of integrated PMS model. Furthermore, only Fitzgerald, et.al's model [11] is meant for service industries.

\section{B. Performance Measurement System (PMS) in Hotel Sector}

Lately in the local hotel sector, the issues of having balanced PMS has become an important issue where funds and resources are shrinking while at the same time stakeholders ask for these organizations to adopt a greater accountability and transparency towards the services provided to the customer.

The existing PMS in the hotel should change accordingly to the changing in their environment in order to improve quality and productivity of the organizations. Early PMS in hotel sector tend to reflect only the financial side of their performances where they are focus mainly on the accounting activities such as margins, cost and expenses allocations. They do not emphasize on the non-financial measures such as the process or the outcomes of customer care deliveries [12]. Rapid growth in economy globally, increase competition in the industry and the existence of continual pressure from the stakeholders of the hotel organizations have made financial figures insufficient in providing information regarding performance to the management, especially in hospitality industry. All of this brings towards more the reasons why the managements of these organizations have to give more attentions towards the improvement of the non-financial measures such as service quality and effective clinical outcomes by establishing the needs to address their current performance shortfalls.

Under the formal financially focused PMS practice by the hotel organizations, the evaluation of these non-financial measures are done separately by the managers, which according to [13], "three major deficiencies in measuring the hotel and integrated delivery systems performances, namely:

- Any effort to improve financial performances will be less effective without taking into consideration of the managers' decisions because they influence the core activities, which are the primary cost drivers at these institutions.

- Managers are likely to resist the management effort in controlling cost by improving productivity and reducing resource utilization if the issues of customer satisfaction and service quality are not dealt with.

- And finally, separate evaluation processes are internally focused that reflect the evaluators' point of views only and dismiss external views from organizations stakeholders, thus affecting the effectiveness of the measurement systems."

\section{Management Control System (MCS)}

Management Control System is an integral part of management responsibilities. The system provides information to managers in order to assist them in making decisions according to their plans and objectives. There are several definitions given by previous authors such as [14], [15]-[17]. Most of the previous work concerning MCS from the management - oriented view have cited [14] definition where he looked at the system process input and output. However, Anthony's definition could be questionable and outdated as it was too restrive concerning the procedure meeting the objectives.

[16], [17] defined MCS as "the formal, information-based routines and procedures managers use to maintain or alter patterns in organizational activities". In a nutshell, control is a policy or procedure that facilitates organization to ensure that its goal and objectives are met. [17] introduced four key variables that must be used for controlling business strategy; belief, boundary, diagnostic and interactive.

According to [18], MCS was important for organizational growth as they liberated top managers' attention from processes that could be controlled by exception and provided them with information when their informal network was overloaded. The emergence of MCS was most important for organizations moving through their growth stage [19], when coordination and control problems could not be solved through informal interaction (as happens during the birth stage). MCS then emerged to formalize this learning by codifying routines and liberating management attention from repetitive tasks.

[20] stated that it was generally recognized in the contingency theory that, for enhanced performance, there needs to be a match between an organization's MCS and its strategy. By extension, the contingency framework suggested that when strategy changes, the MCS also changes. Contingency theory also argued that there was no universally appropriate control system applicable to all situations. As such, the appropriateness of different MCS mechanisms was contingent on the circumstances surrounding the organization. While a number of strategic typology frameworks have been advanced in the literature, this research uses the Simons Lever of Control [17] as the basis for the discussion.

\section{THEORETICAL FRAMEWORK AND HYPOTHESES DEVELOPMENT}

[21] framework, on the other hand, showed the interrelationship between the management control system, firm structure, firm culture and human resource management in order to get the management control system to work according to the strategy. They proposed that effective control systems are highly situational and that the system should be tailored to the nature of each firm. In [21] framework, the firm structure describes the role and responsibility of the members of the firm to make a decision within the firm. The firm culture refers to the shared beliefs attitudes and norms that explicitly or implicitly lead 
managerial actions, while human resource management is the selection, training, evaluation, promotion and termination of employees in order to develop skill and knowledge to boost the firm's strategy.

In order to implement the intended strategy, based on [17] framework which proposed four levers of control which were inter-related each others, i.e. belief systems, boundary systems, diagnostic systems and interactive control systems, the implementation mechanism of [21] framework could be discussed in [17] four levers of control. Therefore, based on [17] and [21] framework, the current study defines the management control system as 'any process or action taken by hotel managers to influence the possibility people in hotels behave in ways to design performance measurement and to allow the emergence of new ideas and opportunities to implement hotels' good strategy'.

\section{A. Hypotheses Development}

The model represented in figure1 aims to test the direct and indirect effects of the management control system respectively on hotel performance. Direct and indirect effect is said to exist when the one variable (an antecedent variable) influences a consequences through another variable (an intervening variable).

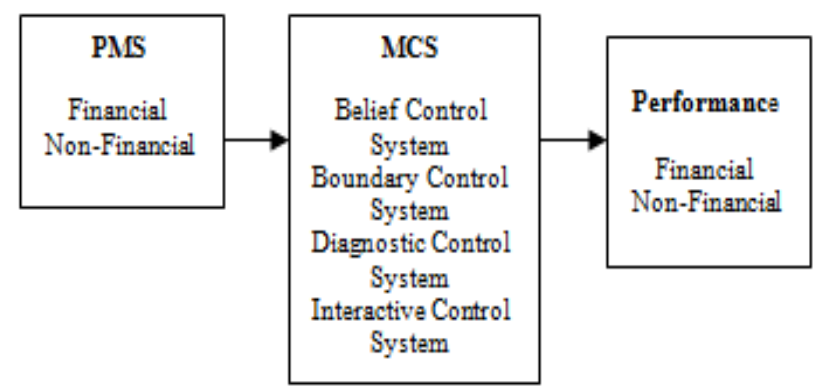

Fig. 1. Research framework.

Based on the conceptualisation of the respective variables discussed above, therefore, the following hypothesis is proposed;

- H1: There is a positive and direct relationship between peformance measurement system (PMS) and management control system (MCS) in the small medium hotel.

- H2: There is a positive and direct relationship between management control system (MCS) and hotel performance.

- H3: There is a positive and direct relationship between peformance measurement system (PMS) and hotel performance.

\section{Methodology}

Data is collected by survey at small medium hotel sectors in the Northern part of Peninsular Malaysia. Total of 250 questionnaires were distributed to managers at 250 small medium-sized hotel in Northern Part of peninsular Malaysia. Out of this number, only 63 were returned and usable. Response rate is about $25.5 \%$.

\section{ANALYSIS AND FINDINGS}

\section{A. Standard Multiple Regression}

Standard Multiple regression is used to simultaneously examine the effects of several independent variables on the single dependent variable. A summary of the regression results of the individual predictors on hotel performance for the above model is presented in Table I.

TABLE I: THE MAIN EFFECT OF THE INDIVIDUAL PREDICTORS ON HOTEL

\begin{tabular}{|c|c|c|c|c|}
\hline \multicolumn{5}{|c|}{ PERFORMANCE } \\
\hline & \multicolumn{2}{|c|}{ Model 1} & \multicolumn{2}{|c|}{ Model 2} \\
\hline Variables & Coefficient & t-value & Coefficient & t-value \\
\hline Constant & 1.115 & $2.850 * *$ & 1.071 & $2.883^{* * *}$ \\
\hline PMS & 0.182 & $2.072 * *$ & & \\
\hline $\begin{array}{l}\text { Non } \\
\text { Financial } \\
\text { Perspective }\end{array}$ & & & 0.453 & $2.854 * *$ \\
\hline $\begin{array}{l}\text { Financial } \\
\text { Perspective }\end{array}$ & & & -2.360 & -1.844 \\
\hline $\begin{array}{l}\text { Boundary } \\
\text { Control } \\
\text { System }\end{array}$ & 0.000 & 0.003 & -0.059 & -0.425 \\
\hline $\begin{array}{l}\text { Belief } \\
\text { Control } \\
\text { System }\end{array}$ & 0.100 & 0.714 & 0.162 & 1.169 \\
\hline $\begin{array}{l}\text { Diagnostic } \\
\text { Control } \\
\text { System } \\
\end{array}$ & 0.327 & $2.648 * *$ & 0.322 & $2.667 * *$ \\
\hline $\begin{array}{l}\text { Interactive } \\
\text { Control } \\
\text { System }\end{array}$ & -0.023 & -.0177 & -0.053 & -0.686 \\
\hline & $\begin{array}{l}R^{2}= \\
F= \\
P=\end{array}$ & $\begin{array}{l}497 \\
283 \\
00 \\
\end{array}$ & $\begin{array}{c}R^{2}= \\
F= \\
P=\end{array}$ & $\begin{array}{l}36 \\
783 \\
00 \\
\end{array}$ \\
\hline
\end{tabular}

Table I shows that 49.7 percent $\left(R^{2}=0.497\right)$ of the level of hotel performance in the model 1 is explained by the independent variables. The $\mathrm{R}^{2}$ was statistically significant with $\mathrm{F}=11.283$ and $\mathrm{p}<0.000$. The analysis shows that among each of the management control system elements, diagnostic control system is the only variable which provides significant explanatory power. On the other hand, Model 2 shows the slightly increase in $\mathrm{R}^{2}$ where 53.6 percent of hotel performance is explained by the independent variables $(\mathrm{F}=10.783, \mathrm{p}=0.000)$ and diagnostic control system also becomes the only variable which provides significant explanatory power. Even though while taking PMS as a whole (Model 1) gives significant explanation to the level of hotel performance, only nonfinancial perspective is actually really contribute to the better performance of the hotel where it explains 45.3 percent of the level of hotel performance (Model 2).

\section{B. Hierarchical Multiple Regression}

As this study intends to examine the influence of the MCS on the relationship between hotel PMS and hotel performance, hierarchical multiple regression is used as suggested by many previous researchers, such as [22] and [23].

According to [22], to test mediation, three (3) regression conditions should be met. First, the independent variable (e.g. Hotel PMS) should affect the mediator (e.g. management control system). Second, the independent variable should have significant effect with the dependent variable (i.e. Hotel Performance) and third, the mediator should affect the dependent variable, when controlling for the independent variable. The linear equations of the relationship mentioned above are:

- MCS $=\alpha+\beta_{1} P M S+\varepsilon$ 
- Performance $=\alpha+\beta_{I} P M S_{i}+\varepsilon$

- Performance $=\alpha+\beta_{I} P M S_{i}+\beta_{I} M C S_{i}+\varepsilon$

where MCS actually represents the existence of each of the management control system elements; Belief Control System, Boundary Control System, Diagnostic Control System and Interactive Control System.

Correlation analysis shows that PMS is correlated to an each of the four selected individual management control system (i.e.; Belief Control System, Boundary Control System, Diagnostic Control System and Interactive Control System) at $\mathrm{p}<0.01$. Thus the result confirms the first requirement of the mediation process.

The second requirement for the mediation effect is that PMS must significantly affect hotel performance. As [22] suggested that the independent variable must be related significantly to dependent variable. As shown in correlation analysis, hotel PMS and hotel performance are significantly correlated. The regression result in which hotel performance was regressed on hotel PMS is shown in Table II, Model 1. As indicated in Table II, PMS was significantly related to hotel performance in Model 1 (Beta 0.182 and $\mathrm{p}<0.05$ ). This result suggests that PMS was a significant indicator to hotel performance. Thus, the second requirement for mediation was confirmed.

To demonstrate mediation, it must be shown that the PMS is related to hotel performance, when hotel performance is regressed on both PMS Strategy and each of management control system element. Refer to Table II, Model 2 - Model 5 show that each of the management control system elements (i.e.; Belief Control System, Boundary Control System, Diagnostic Control System and Interactive Control System) is significantly related to hotel performance.

TABLE II: HieraRCHICAL MULTIPLE REgRESSION: SMALl MEDIUM HOTEL PERFORMANCE

\begin{tabular}{|c|c|c|c|c|c|}
\hline Variables & Model 1 & Model 2 & Model 3 & Model 4 & Model 5 \\
\hline PMS & $\begin{array}{l}0.366 * * \\
(0.087)\end{array}$ & $\begin{array}{l}0.222 \\
(0.088)\end{array}$ & $\begin{array}{l}0.243 \\
(0.084)\end{array}$ & $\begin{array}{l}0.185 \\
(0.078)\end{array}$ & $\begin{array}{l}0.145 \\
(0.090)\end{array}$ \\
\hline $\begin{array}{l}\text { Boundary } \\
\text { Control System }\end{array}$ & & $\begin{array}{l}0.346^{* * *} \\
(0.094)\end{array}$ & & & \\
\hline $\begin{array}{l}\text { Belief Control } \\
\text { System }\end{array}$ & & & $\begin{array}{l}0.348 * * \\
(0.089)\end{array}$ & & \\
\hline $\begin{array}{l}\text { Diagnostic } \\
\text { Control System }\end{array}$ & & & & $\begin{array}{l}0.359 * * \\
(0.064)\end{array}$ & \\
\hline $\begin{array}{l}\text { Interactive } \\
\text { Control System }\end{array}$ & & & & & $\begin{array}{l}0.305 * * \\
(0.068)\end{array}$ \\
\hline $\mathrm{R}^{2}$ & $0.225 * *$ & $0.368 * *$ & $0.381 * *$ & $0.491 * *$ & $0.421 * *$ \\
\hline $\mathrm{R}^{2}$ Change & & 0.143 & 0.156 & 0.266 & 0.196 \\
\hline
\end{tabular}

\begin{tabular}{|c|c|c|c|c|}
\hline $\begin{array}{l}\text { Boundary } \\
\text { Control System }\end{array}$ & $\begin{array}{l}0.346 * * \\
(0.094)\end{array}$ & & & \\
\hline $\begin{array}{l}\text { Belief Control } \\
\text { System }\end{array}$ & & $\begin{array}{l}0.348^{* * *} \\
(0.089) \\
\end{array}$ & & \\
\hline $\begin{array}{l}\text { Diagnostic } \\
\text { Control System }\end{array}$ & & & $\begin{array}{l}0.359 * * \\
(0.064)\end{array}$ & \\
\hline $\begin{array}{l}\text { Interactive } \\
\text { Control System }\end{array}$ & & & & $\begin{array}{l}0.305^{* * *} \\
(0.068)\end{array}$ \\
\hline PMS & $\begin{array}{l}0.222 \\
(0.088)\end{array}$ & $\begin{array}{l}0.243 \\
(0.084)\end{array}$ & $\begin{array}{l}0.185^{*} \\
(0.078)\end{array}$ & $\begin{array}{l}0.145 \\
(0.090)\end{array}$ \\
\hline $\mathrm{R}^{2}$ & 0.368 & 0.381 & $0.491^{*}$ & 0.421 \\
\hline $\mathrm{R}^{2}$ Change & 0.067 & 0.085 & 0.048 & 0.025 \\
\hline
\end{tabular}

The standardized coefficient $(\beta)$ provides evidence a significant direct link between Belief Control System; Boundary Control System; Diagnostic Control System; Interactive Control System and hotel Performance, while controlling PMS. All of them are significant at $\mathrm{p}<0.001$. The third requirement for mediation is supported.

In order to reach the perfect mediation, the independent variable should have no significant effect on the dependent variable, when the mediator is controlled for [22]. Therefore, the second test is done to Model 2, Model 3, Model 4 and Model 5. By controlling for each management control system element, the variance in hotel Performance, explained by PMS declined to non-significant level except for diagnostic control system where significant at $\mathrm{p}<0.05$.

In sum, the result suggests that there is complete mediation for each element of MCS (i.e.; Belief Control System; Boundary Control System and Interactive Control System) and partial mediation for Diagnostic Control System on the relationship between hotel PMS and hotel performance. The results also support the argument which said that the development of PMS will influence the overall performance in small medium hotel sector through the acting of Belief Control System; Boundary Control System; Diagnostic Control System; and Interactive Control System.

\section{DISCUSSION AND CONCLUSION}

Result reveals that MCS is found to be positively correlated to performance measurement system design and overall hotel performance. However, the finding does not postulate that hotel performance will be influenced by the MCS except for diagnostic control system. Even though there is a positive correlation between all types of MCS and hotel performance, the hotel performance does not necessarily depend on whether or not the hotels integrate MCS in their PMS design.

This finding contradict with the findings of studies carried out by [24] and [25] which report a positive and significant effect of MCS on performance. However, [24] study on environmental performance in manufacturing firm and [25] studied MCS on financial performance in general. These contradictory findings may be due to the different setting studied.

\section{A. Interactive Control System}

Interactive control system was not found to be significant indicator to the level of hotel performance. This finding contrasts with the study done by [24] which found positive significant relationship. However, this study found that good PMS design was a good indicator of the use of an interactive control system. There was a positive and significant relationship between PMS and the interactive control system (refer to Table II). This finding suggests that the use of interactive control system would not boost hotel performance unless top management and employees are involved adequately equipped with the relevant knowledge and skill. Even though SME's hotels employ PMS, without staffs knowledge and skill, the result suggests that hotel performance will not improve. However, as [17] suggests, an interactive control system may motivate firms to search for new strategies and to adapt to the new strategies and 
practices to enhance performance. For example, even though the top management and employees are involved personally and interactively in PMS and decision making, if they do not have a sound skill and knowledge base regarding the issues of performance measurement, their decision making ability may be limited. This finding may also be related to several factors such as the setting of the firm, resistance of adapting to a new culture, an adequate rewards system designed, and may also related to the size of the hotel.

Therefore, this study suggests that the following factors might influence the level of hotel performance when designing appropriate PMS.

- Hotel staff should be equipped with adequate skill and knowledge by conducting regular training regarding performance measurement system.

- Implement a sensible bonus and reward scheme for staff which rewards them for improving hotel performance.

- Educate customers to accept a new emerging culture in the hotel environment.

\section{B. Boundary Control System}

The boundary control system was not found to be significantly related to hotel performance. However, this study found that good PMS design was a good indicator of the use of a boundary control system. There was a positive and significant relationship between PMS and boundary control system (refer to Table II). By integrating boundary control system in hotel PMS, hotels will have a proper plan to control their costs and revenues such as the cost of training to enhance skill of accounting and control staffs in order to have and prepare complete and accurate record keeping for short term boundary. Considering this result, however, SME hotels may still be emphasizing on the use of traditional PMS [26], [27], which are not only backward but unbalanced and most likely to impede the firms effort from becoming strategically competitive entity in the context of current volatile business environment.

\section{Belief Control System}

Belief control system was related to the culture of the firm where it was surrounded with the vision and mission which shared and communicates to all of the employees. This study found not to be significantly related and contribute to the level of hotel performance. This result suggess that belief control system does not act as an indicator to ensure hotels will achieve better performance. [28] suggests that firms should integrate belief control system in PMS design to increase people's willingness to share knowledge to create values and change their beliefs in measuring performance. Performance does not only refer to financial indicator but also need to balance with nonfinancial indicator. If people in SMEs hotel does not willing to change, the objective to compete with large hotel would likely not be achieved.

Most of the SMEs hotels who respond to the study were categorised as budget and economy hotels and employed customer differentiation strategy. This strategy is referred to creating services which unique that can attract more customer to come. Therefore it is obvious that with this strategy, SMEs hotels more focus on profit in order to measure performance. The more customers, the higher the profit and the better the performance is. Thus, with this beliefs, adaptability to a new belief is more difficult and this finding is similar to the traditional control system which is formal and familiar to small medium firms [14].

In the other hand, this insignificant finding may be due to the balanced PMS which use BSC as performance measurement tools being a new concern in the Malaysian SMEs hotels and not currently properly implemented by the hotel sectors. One reason may be related to interactive action from the top management and employees. On the other hand, basically, BSC is mostly used by the large hotels. Interview findings also suggests that belief and culture build from day-to-day experience. Therefore, being a BSC followers and believers are not one-day experience. In order to integrate the believe in PMS design, the management and employees should be ready and flexible to accept this new ideas and create a new culture extensively.

\section{Diagnostic Control System}

The diagnostic control system was found to be significantly and positively related to hotel performance. The result also shows that PMS has strong relationship with diagnostic control system. The result suggest that the more hotels apply diagnostic control system in designing PMS, the better PMS will be. As [29] mentioned that diagnostic control system such as accounting information system is important in communicating practice and strategy to stakeholders. Therefore, by actively applied diagnostic control system, stakeholders know that management monitor their performance frequently with appropriate tools which is proper design of PMS. This study suugests that if the hotel has extensively use their system in tracking progress and monitoring results with expectation, the performance will likely to enhance significantly.

\section{E. PMS, MCS and Performance in Small Medium Hotel Sector}

Previous study examined the MCS and PMS separately. This study investigates the inter-relationship of PMS, MCS and hotel performance . Primary contribution is recognition of the mediating effect of MCS on hotel performance. The first requirement to test the mediation effect was met where PMS is significantly related to each of MCS types. This relationship also coincides with the correlation analysis where the correlation coefficent suggest significant correlation between PMS and each of MCS levers individually.

The standardised coefficent also provide support for the existence of a direct link between PMS and hotel performance which is shown in Table II, Model 1. Thus the second requirement for the mediation is supported. Table II also shows that all element of MCS are significant mediators to hotel performance. The result indicate that there were strong indirect effects of PMS on hotel performance acting through MCS. The relationship between PMS and hotel performance can be influenced by integrating each elements of MCS in PMS design.

The effect of MCS on hotel performance can be explained by the increase in $\mathrm{R}$ square (refer to Table II Model 2). For example, integrating boundary control system in PMS design will increase R square for about 14.3 percent 
and this strong relationship is also supported by the strong direct effect between boundary control system and hotel performance. This study supports the argument given by [30] where they used budgeting control system as a boundary control system. They found that by using budgeting control system, performance will be increased. Similar to this study, by integrating boundary control system (short and long term boundary) in PMS design; such as keeping proper accounting record and doing job rotation in ensuring PMS design consider those important activities will likely to enhance hotel performance.

Table II Model 3 also highlighted the significant explanatory power of hotel performance when integrating belief control system in PMS design. R square increase for about 15.6 percent and this is also explained by the strong relationship between belief control system and hotel performance. The plausible explanation regarding the significant indirect effect on hotel performance through the acting of belief control system is likely to be due to the increasing of awareness among employees of the hotels. It seems that they are all positively hold the same belief and culture that by having good and proper PMS design according to vision and mission will likely enhance their performance. PMS design also should not focus to only financial indicator but also should highlight the nonfinancial indicator along, as what implemented by large hotels.

Model 4 in Table II also suggests the diagnostic control system increase the explanatory power of the link between PMS and hotel performance for about 26.6 percent, the highest among the other element of MCS. By integrating diagnostic control system when designing PMS in measuring hotel performance help SMEs hotels aware that tracking progress towards goals, monitoring results of hotel operation, review key measures and comparing outcome with expectation will likely assist management of the hotels to improve their performance. In comparison to the manufacturing sector, the hotel sector appears to depend far less on physical resources for their basic operation [30], however, it does not mean that there is no need for measuring system to be properly designed.

Similar to this, interactive control system is also contribute to the strong relationship between PMS and hotel performance. The effect of the integrating interactive control system in PMS design can be explained by the increase in R square for about 19.6 percent (Table II Model 5). The strong indirect effect is more likely to result from the strong relationship between an interactive control system and hotel performance. This result is similar to that of [28] and [32] where they found that increase in performance could result from a better bonus system (one of the indicators of the interactive control system). The expected result is supported since the interactive control system is known to be an important control system in order to emerge new ideas and share knowledge regarding new approach [17] of PMS design in order to be more effective and efficient in tracking performance of the hotels.

The results provide evidence on the link between PMS and MCS. As mentioned by [33] that MCS do not operate in isolation, but they have to be considered as a package. This study uses Simons' Levers of Control - Beliefs Control
System, Boundary Control System, Diagnostic Control System and Interactive Control System. The results support the argument that PMS are able to influence hotel performance through various types of formal and informal control used by hotels.

\section{ACKNOWLEDGEMENT}

Authors acknowledge Universiti Utara Malaysia and Malaysian Government for their financial support through Financial Research Grant Scheme (FRGS).

\section{REFERENCES}

[1] P. Cocca and M. Alberti, "A framework to assess performance measurement systems in SMEs," International Journal of Productivity and Performance Management, vol. 59, no. 2, pp. 186200, 2010.

[2] A. Neely, J. Mills, K. Platts, H, Richards, M. Gregory, M. Bourne, and M. Kennerley, "PMS design: developing and testing a processbased approach," International Journal of Operations \& Production Management, vol. 20, no. 10, pp. 1119-1145, 2002.

[3] M. Bourne, M. Wilcox, A. Neely, and K. Platts, "Designing, implementing and updating performance measurement systems," International Journal of Operations and Production management, vol. 20, no. 7, pp. 754-771, 2000.

[4] P. Garengo, S. Biazzo, and U. Bititci, "Performance measurement systems in SMEs: A review for a research agenda," International Journal of Management Reviews, vol. 7, no. 1, pp. 25-47, 2005.

[5] A. Hanif and I. Manarvi, "Performance based segmentation of small and Medium Entreprise: A data mining approach," in Proc. International Conference on Computers and Industrial Engineering, 2009, pp. 1509-1513.

[6] S. Sousa, and E. Aspinwell, "Development of a performance measurement framework for SMEs," Total Quality Management, vol. 21, no. 10, pp. 475-501, 2010.

[7] P. Cocca and M. Alberti, "SMEs' three-step pyramid: A new performance measurement framework for SMEs," in Proc. the 16th International Annual EurOMA Conference "Implementation realizing Operations Management knowledge," 14-17 June, 2009, Göteborg.

[8] A. Chennell, S. Dransfield, N. Field, I. Saunders, and D. Shaw, "OPM: A for organizational performance measurement," in conference proceedings performance measurement, 2000, Cranfield University, pp. 96-103

[9] E. Laitinen, "Framework for small business performance measurement: towards integrated PMS," presented at Vasaa conference, The University of Vasaa, 1996.

[10] H. Raintenan and J. Holtari, "Performance analysis in finnish SMEs," Eleventh International Working Seminar on Production Economics, IGLS Austria, vol. 21 -25, February, 2000.

[11] L. Fitzgerald, R. Johnston, T. J. Brignall, R. Silvestro, and C. Voss, "Performance measurement," in Service Businesses, CIMA, London, 1991.

[12] L. J. Stewart and A. Lokamy III, "Improving competitiveness through performance measurement system," Healthcare Financial Management, vol. 55, no. 12, pp. 46-50, 2001.

[13] K. Walker. "Efficiency and effectiveness reviews in health care organization," Journal of Cost Management, pp. 80-86, Spring 1996.

[14] R. N. Anthony, Planning and Control Systems: A Framework for Analysis, Boston: Harvard Business, Division of Research, MarchApril 1965, pp. 18-24.

[15] R. H. Chenhall, "Management control system design within its organizational context: findings from contingency-based research and directions for the future," Accounting, Organisations and Society, vol. 28, no. 2-3, pp. 127-168, 2003.

[16] R. Simons, "How new top manager use control systems as levers of strategic renewal," Strategic Management Journal, vol. 15, no. 3, pp. 169-189, 1994.

[17] R. Simons, "Levers of control: how managers use innovative control systems to drive strategic renewal. boston: harvard business school press," Harvard Business Review, vol. 80-88, March-April 1995.

[18] E. Flamholtz and Y. Randle, Growing Pains: Transitioning from an Entrepreneurship to a Professionally Managed Firm, 2000, New Rev. ed. Jossey-Bass: San Francisco.

[19] K. Moores and S. Yuen, "Management accounting system and organizational configuration: A life-cycle perspective," Accounting, Organisation and society, vol. 26, pp. 351-389, 2001. 
[20] R. Kober et al., "The interrelationship between management control mechanisms and strategy," Management Accounting Research, vol. 18, pp. 425-452, 2007.

[21] R. N. Anthony and V. Govindarajan, Management Control System, $10^{\text {th }}$ ed., New York: McGraw Hill, 2001.

[22] R. M. Baron and D. A. Kenny, "The moderator-mediator variable distinction in socialpsychological research: Conceptual, strategic, and statistical considerations," Journal of Personality and Social Psychology, vol. 51, pp. 1173-1182, 1986.

[23] D. S. Sharma, "The differential effect of environmental dimensional, size and structure on budget system characteristics in hotels," Management Accounting Research, vol. 13, pp. 101-130, 2002.

[24] J. F. Henri and M. A. Journealt, "Eco-control: the influence of MCS on environmental and economic performance," Accounting, Organizations and Society, vol. 35, pp. 63-80, 2010.

[25] M. Tekavčič and D. Peljhan, "Insights into managerial tools related to cost management in Slovenia companies," Rijeka Faculty of Economics Journal of Economics and Business, vol. 21, no. 1, pp. 83$99,2003$.

[26] M. G. Brown, Keeping Score: Using the Right Metrics to Drive World Class Performance, Quality Resources, New York, USA, 1996.

[27] R. Kaplan and D. Norton, "Using the balanced scorecard as a strategic management system," Harvard Business Review, pp. 75-85, Jan-Feb, 1996.

[28] C. B. Hunt and E. R. Auster, "Proactive environmental management: avoiding the toxic trap," MIT Sloan Management Review, vol. 31, no. 2, pp. 7-18, 1990.

[29] S. Schaltegger, R. Burritt, and H. Petersen, An Introduction to Corporate Environmental Management-Striving for Sustainability, 2003, Sheffield, UK: Greenleaf.

[30] M. A. Abernethy and P. Brownell, "The role of budgets in organizations facingstrategic change: an exploratory study." Accounting, Organizations and Society, vol. 24, pp. 189-204, 1999.

[31] Blair, and Hitchcock, Business and Environment, Taylor and Francis Group, 2001.
[32] V. Govindarajan and A. K. Gupta, "Linking control systems to business unit strategy: impact on performance," Accounting, Organization \& Society, vol. 10, no. 1, pp. 51-66, 1985.

[33] T. Malmi and D. A. Brown, "Management control systems as a package - Opportunities, challenges and research directions," Management Accounting Research, vol. 19, no. 4, pp. 287-300, 2008.

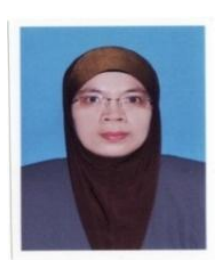

Che Zuriana Muhammad Jamil is a senior lecturer in Management Accounting at College of Business, University of Utara Malaysia since 10 years ago. She obtained her $\mathrm{Ph} . \mathrm{D}$. degree from Bangor University, Wales, United Kingdom in 2008. Her research interestsare related to environmental management control system, performance measurement system and environmental management practice in all types of industries.She has experienced teaching and conducting research in management control system and environmental management course. She has published several articles in the local and international refereed journals.

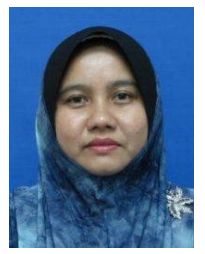

Rapiah Mohamed is senior lecturer of accounting at the School of Accountancy at the Universiti Utara Malaysia. Her undergraduate degree (accounting) is from Universiti Utara Malaysia, her MBA (Accounting) from Monash University, and her $\mathrm{PhD}$ from the UniversitiTeknologi MARA (UiTM). Her research areas are performance measurement system, management control system and corporate social responsibility.She has published several articles in the local and international refereed journals. She is also presenter at various local and international conferences. Her current research projects are corporate sustainability and performance measurement of SMEs. 